\title{
Follicular waves and circulating concentrations of gonadotrophins, inhibin and oestradiol during the anovulatory season in mares
}

\author{
F. X. Donadeu ${ }^{1}$ and O. J. Ginther ${ }^{1,2 *}$ \\ ${ }^{1}$ Department of Animal Health and Biomedical Sciences, University of Wisconsin, Madison, \\ WI 53706, USA; and ${ }^{2}$ Eutheria Foundation, Cross Plains, WI 53528, USA
}

Follicular waves and associated circulating hormone concentrations were studied during the anovulatory season in pony mares $(n=8)$. Follicles were monitored by ultrasonography and a blood sample was taken daily from 29 January until ovulation (mean, 28 April). A midanovulatory period (largest follicle, $16.0 \pm 0.5 \mathrm{~mm}$ in diameter) and transitional period (largest follicle, $22.4 \pm 0.5 \mathrm{~mm}$ ) were distinctive in each mare. The two periods were delineated by an increase in the diameter of the largest follicle to $\geqslant 21.0 \mathrm{~mm}$. Follicular waves, identified by significant increases in the mean diameter of the second to sixth largest follicles, were detected during both the mid-anovulatory and transitional periods. The mean number of follicles $\geqslant \mathbf{1 5 . 0} \mathbf{~ m m}$ in diameter and the diameter of the second to sixth largest follicles increased in association with statistically identified FSH surges. The pattern of the FSH concentration changes during surges did not change during the mid-anovulatory and transitional periods. During the declining portion of the FSH surge, follicle growth continued and circulating total inhibin increased, indicating suppression of FSH by inhibin from the growing follicles. Circulating oestradiol or LH did not change relative to wave emergence. Results indicated that follicular waves occurred during the second-half of the anovulatory season, even during the period of lowest follicular activity. On a temporal basis, follicular wave emergence was stimulated by surges in circulating $\mathrm{FSH}$. However, the increase in follicle growth to $\geqslant 21.0 \mathrm{~mm}$ in diameter for the wave at the beginning of the transitional period and for the subsequent waves was not attributable to a change in the characteristics of the associated FSH surges.

\section{Introduction}

Mares are seasonal breeders, with maximal ovulatory activity during long days (ovulatory season) and minimal activity during short days (anovulatory season). During the middle of the anovulatory season, only small $(<15 \mathrm{~mm}$ in diameter) follicles may be present. The follicles grow to increasingly larger mean diameters during the last 2-3 months of the anovulatory season or transitional period, culminating in the development of an ovulatory follicle (reviewed by Ginther, 1992). In transitional mares, one to several large $(>30 \mathrm{~mm})$ anovulatory follicles may develop periodically preceding the development of the ovulatory follicle (Ginther, 1990; Watson et al., 2002). Follicular waves are defined as the synchronous development of a cohort of follicles (reviewed in Ginther, 1992). During the ovulatory season, waves are usually associated with the development of large $(\geqslant 30 \mathrm{~mm}$ ) dominant follicles (major waves), but waves may occur without a dominant follicle (minor waves). Major waves have been presumed to occur

*Correspondence

Email: ojg@ahabs.wisc.edu during the transition between the anovulatory and ovulatory seasons based on the periodic detection of large (>30 mm) anovulatory follicles (Ginther, 1990; Watson et al., 2002). These studies have not demonstrated adequately that the large follicle developed from a cohort of follicles. In addition, it is not known whether the small follicles during the middle of the anovulatory season resulted from minor waves.

Differences in the proportion and type of pituitary gonadotrophs have been described between anovulatory and ovulatory mares (Eagle and Tortonese, 2000). However, pituitary FSH concentrations are not different between the anovulatory and ovulatory seasons (Silvia et al., 1986). Mean FSH concentrations (Freedman et al., 1979; Turner et al., 1979; Hines et al., 1991) and pulse amplitude (Hines et al., 1991) were high during the middle of the anovulatory season and declined during the last 60 days of the season with a more pronounced decline during the last 20 days (Freedman et al., 1979). During the gradual 60 day decline in mean FSH concentrations, the follicles grew to increasingly large mean diameters (Freedman et al., 1979). Surges in FSH are associated with the emergence of follicular waves during the ovulatory season (Ginther and Bergfelt, 1993) and have been detected during the early 
development of large (> $30 \mathrm{~mm}$ ) anovulatory follicles near the end of transition (Ginther, 1992; Watson et al., 2002). The occurrence of $\mathrm{FSH}$ surges and the temporal relationships between follicle development and FSH surges have not been reported for the middle of the anovulatory season. Clarification of the follicle-FSH relationships in anovulatory mares likely will require shorter intervals between evaluations and the development of common reference points for normalization among mares.

In contrast to FSH, mean pituitary (Silvia et al., 1986) and circulating (Oxender et al., 1977; Freedman et al., 1979; Fitzgerald et al., 1987; Alexander and Irvine, 1991) concentrations of $\mathrm{LH}$ are minimal during most of the anovulatory season and increase shortly before the first ovulation of the year. An increase in circulating LH pulse frequency and a decrease in pulse amplitude occur throughout the transition into the ovulatory season (Fitzgerald et al., 1987). Similar to LH, mean circulating oestradiol concentrations remain low during most of the anovulatory season and increase during the last stages of the transitional period in association with the development of large follicles (Oxender et al., 1977; Freedman et al., 1979; Seamans and Sharp, 1982) that have increased vascularity (Watson and Al-zi'abi, 2002) and steroidogenic competence (Davis and Sharp, 1991; Bogh et al., 2000).

The temporal relationships among the day-to-day changes in circulating inhibin concentrations and $\mathrm{FSH}$ concentrations and follicle diameter have been reported for the ovulatory season (Donadeu and Ginther, 2001; Bergfelt et al., 2001) but not within the various stages of the anovulatory season. In a recent study (Watson et al., 2002), mean plasma concentrations of inhibin $A$ and inhibin isoforms containing pro- and $-\alpha C$ were higher during the development of large transitional follicles $(25-40 \mathrm{~mm})$ than during winter, when only small follicles were present. In stallions, inhibin concentrations were lowest during winter and highest during summer (Roser et al., 1994; Nagata et al., 1998).

The present study in mares was done to test the hypotheses that follicular waves, defined as emergence of a cohort of follicles, occur during the middle of the anovulatory season and during the transition into the ovulatory season and that the waves at all stages are temporally associated with changes in circulating concentrations of $\mathrm{FSH}$. In addition, the day-to-day relationships among changes in follicle diameters and circulating concentrations of $\mathrm{FSH}, \mathrm{LH}$, total inhibin and oestradiol were characterized from the middle of the anovulatory season until the first ovulation of the year.

\section{Materials and Methods}

\section{Experimental animals and follicles}

Non-lactating pony mares $(n=8)$ of mixed breeding, aged 9-16 years, body weight 230-400 kg, were kept under natural light in an open shelter and outdoor paddock in the
Northern Hemisphere (latitude, $43^{\circ} \mathrm{N}$; WI). Mares were fed alfalfa and grass hay and had free access to water and mineralized salt. Ovaries were monitored transrectally once a day with an ultrasound scanner equipped with a $5 \mathrm{MHz}$ linear-array transducer (Aloka SSD-500V; Aloka, Wallingford, CT), beginning on 29 January and continuing until the first ovulation of the year. At each scanning session, the number and diameter of follicles $\geqslant 10.0 \mathrm{~mm}$ in diameter were recorded, the diameter being estimated by comparison with the graduation marks on the scanner screen, and the six largest follicles were measured with electronic calipers by taking the mean width and length from a frozen image (Ginther, 1995).

\section{Blood sampling and hormone assays}

A jugular blood sample was collected daily from each mare for measurement of circulating hormone concentrations. Blood samples were immediately centrifuged at $1500 \mathrm{~g}$ for $16 \mathrm{~min}$ and the plasma fraction was separated and stored at $-20^{\circ} \mathrm{C}$. Plasma concentrations of $\mathrm{FSH}$ and $\mathrm{LH}$ were measured by double-antibody radioimmunoassays, as described for mares (Donadeu and Ginther, 2002). Intra-assay and interassay CVs were $12.4 \%$ and $13.4 \%$ for $\mathrm{FSH}$ and $7.8 \%$ and $5.5 \%$ for $\mathrm{LH}$, respectively. Assay sensitivities were $1.4 \mathrm{ng} \mathrm{FSH} \mathrm{ml}^{-1}$ and $0.1 \mathrm{ng} \mathrm{LH} \mathrm{ml}{ }^{-1}$. For all hormones, sensitivity was calculated by subtracting two standard deviations from the mean maximum percentage binding and averaging over all assays.

Concentrations of total (immunoreactive) inhibin were measured in plasma by a double-antibody radioimmunoassay kit (Institute of Reproduction and Development, Monash Medical Center, Clayton), as described by Donadeu and Ginther (2001). The antibody recognizes dimeric inhibin forms, as well as free $\alpha$-subunit forms (Roser et al., 1994). Intra-assay and interassay CVs were $9.1 \%$ and $15.0 \%$, respectively, and the sensitivity was $5.8 \mathrm{ng} \mathrm{ml}^{-1}$.

Plasma concentrations of oestradiol were measured by a double-antibody radioimmunoassay kit (Double Antibody Estradiol, Diagnostic Products Corporation, Los Angeles) after extracting the samples with ether, as described for mare samples (Gastal et al., 1999). Intra-assay and interassay $\mathrm{CV}$ s were $14.8 \%$ and $17.5 \%$, respectively, and the sensitivity was $0.03 \mathrm{pg} \mathrm{ml}^{-1}$.

\section{Follicle and hormone endpoints}

For analyses involving measurements over time, the endpoints for largest follicle(s) and number of follicles refer to follicle(s) for each day without consideration of day-today identity. Follicular waves were detected by an adaptation of a mathematical method described in mares by Ginther and Bergfelt (1992a). The diameters of the second to sixth largest follicles were statistically analysed within each mare. Data from the largest follicle and from any follicle reaching $>28 \mathrm{~mm}$ were excluded to minimize the variation within days (Ginther and Bergfelt, 1992a). A 
significant increase in the mean diameter of the second to sixth largest follicles was used to identify the beginning of a follicular wave. The day of emergence of a wave was defined by the beginning of the significant increase.

Surges in FSH and fluctuations in oestradiol in daily circulating concentrations within each mare were differentiated from variation due to extraneous factors (variation in sampling or assaying technique), as described by Fitzgerald et al. (1985) in mares. The CV of the values composing the ascending and descending portions of the suspected surge or fluctuation had to be at least three times higher than the mean intra-assay $\mathrm{CV}$. In addition, a given surge or fluctuation had to include values from at least 2 days. The highest value associated with an identified surge or fluctuation was defined as a peak. The amplitude of a surge or fluctuation was defined as the difference between concentrations at the peak and concentrations at the preceding nadir.

Inspection of follicle characteristics for individual mares indicated the presence of three distinct periods of follicle activity during the second-half of the anovulatory season in each mare. Therefore, data for individual mares were partitioned into a mid-anovulatory period, a transitional period, and a preovulatory period. The mid-anovulatory period was defined by a diameter of the largest follicle of $<21.0 \mathrm{~mm}$. The beginning of the transitional period was defined by the first increase in the diameter of the largest follicle that resulted in $a \geqslant 21.0 \mathrm{~mm}$ follicle. The day the ovulatory follicle reached $\geqslant 21.0 \mathrm{~mm}$, as determined retrospectively, was used to separate the transitional and preovulatory periods.

Changes in follicle and hormone endpoints during the mid-anovulatory and transitional periods were studied by analysing data from 34 days before to 34 days after the beginning of the transitional period. This interval was chosen based on the maximum availability of data from the mares. Follicle and hormone endpoints were also analysed from 4 days before to 10 days after the beginning of the preovulatory period. The relationships between follicular waves and circulating hormone concentrations were compared for identified waves during the mid-anovulatory period, beginning of the transitional period, and middle of the transitional period. In mares with multiple waves during the mid-anovulatory period, the last wave during the period was used for analysis. In each case, data were normalized to the beginning of waves, using data from 7 days before to 5 days after wave emergence. In addition, the relationships between identified FSH surges and follicle activity were compared between the mid-anovulatory and transitional periods. This was done by analysing the changes in mean diameter of the second to sixth largest follicles and in the number of follicles $\geqslant 15.0 \mathrm{~mm}$ in diameter relative to an FSH peak for identified FSH peaks that were central to each of the two periods. Within each mare the changes in the two follicle endpoints were calculated by subtracting the value on the day of the FSH peak from all other values. Data from 1 day before to 3 days after the peak were used. Means for single-point endpoints were compared among the midanovulatory, transitional and preovulatory periods or among waves occurring during the mid-anovulatory and transitional periods. The mean for each period or wave was determined for each individual mare and the degrees of freedom used in the comparisons were based on the number of mares.

\section{Statistical analyses}

Data for each end point were tested for normality with a Kolmogorov-Smirnov test (SAS Institute Inc., 1989) and normalized by log-transformation when the probability level $(P)$ was $P<0.01$. Data were then analysed by the SAS MIXED procedure (SAS Institute Inc., 1995) using the animal as the random term and accounting for the autocorrelation among samples taken over time. For the analysis of sequential data involving different periods, the animal within period was used as the random term. Main effects of day, period and the interaction were determined. Tukey's tests were used in all statistical analyses for comparisons among means. Significance was considered at $P<0.05$, whereas probabilities from $>0.05$ to $<0.1$ were considered as approaching significance.

\section{Results}

\section{Follicular periods}

The duration of the interval from 29 January to the first ovulation of the year was 69, 77, 82, 85, 86, 89, 111 and 122 days in the eight mares (mean, $90.1 \pm 6.2$ days). Mean date of ovulation was 28 April. Follicle and hormone profiles are shown for three individual mares, including defined periods and identified waves (Fig. 1). The maximal diameter of the largest follicle at any day during the midanovulatory period ranged from 17.8 to $20.8 \mathrm{~mm}$ in individual mares. The transitional period began 31-93 days before ovulation (mean, $51.5 \pm 7.3$ days). During the transitional period, an anovulatory follicle reached $\geqslant 30 \mathrm{~mm}$ in diameter in three of eight mares. In the remaining five mares, the largest follicle during the transitional period was 22.4 to $28.9 \mathrm{~mm}$. The ovulatory follicle reached $\geqslant 21.0 \mathrm{~mm}$ (beginning of the preovulatory period) 6-14 days (mean, $10.1 \pm 0.8$ days) before the first ovulation of the year.

Mean follicle and hormone profiles from 34 days before to 34 days after the beginning of the transitional period and for 4 days before to 10 days after the beginning of the preovulatory period are shown (Fig. 2). The mean number of follicles $\geqslant 15.0 \mathrm{~mm}$ diameter increased $(P<0.05)$ over the first 8 days of the transitional period and decreased $(P<0.05)$ during the preovulatory period. The mean diameter of the largest follicle increased $(P<0.0001)$ during the first 8 days of the transitional period; a further increase $(P<0.0001)$ occurred during the preovulatory period, after the ovulatory follicle had become the largest follicle.

No effect of day $(P>0.1)$ was found for $\mathrm{FSH}$ 

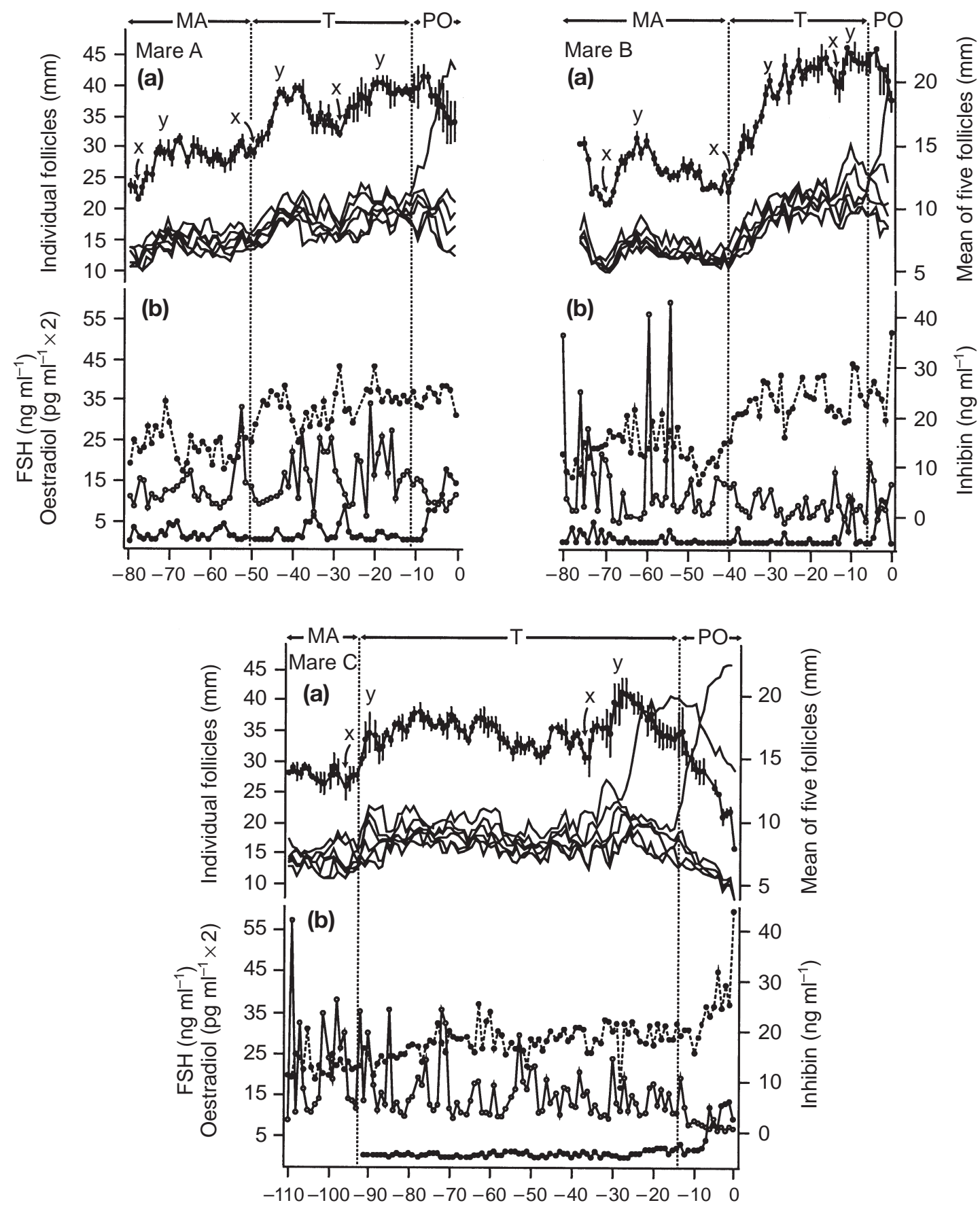

Days relative to ovulation

Fig. 1. Daily values for follicle and hormone endpoints from 29 January to the first ovulation of the year in three individual mares (A, B, C), showing (a) mean diameter \pm SEM of the second to sixth largest follicles (- diameters of each of the six largest follicles (-), and (b) concentrations of circulating total inhibin (------), FSH (—O_) and oestradiol (- - V . Vertical dotted lines separate the mid-anovulatory period (MA), transitional period $(\mathrm{T})$ and preovulatory period $(\mathrm{PO})$. Days corresponding to emergence $(\mathrm{x})$ and maximum diameter $(\mathrm{y})$ of each identified wave are indicated on the mean diameters of the second to sixth largest follicles.

concentrations for the 34 days before and after the beginning of the transitional period (Fig. 2). However, FSH concentrations decreased $(P<0.05)$ from 2 days before to 3 days after the beginning of the preovulatory period and then remained low until ovulation. Surges in circulating FSH were identified in all mares during the mid-anovulatory period (one to three surges per mare), in seven mares during the transitional period (one to five surges) and in only two 


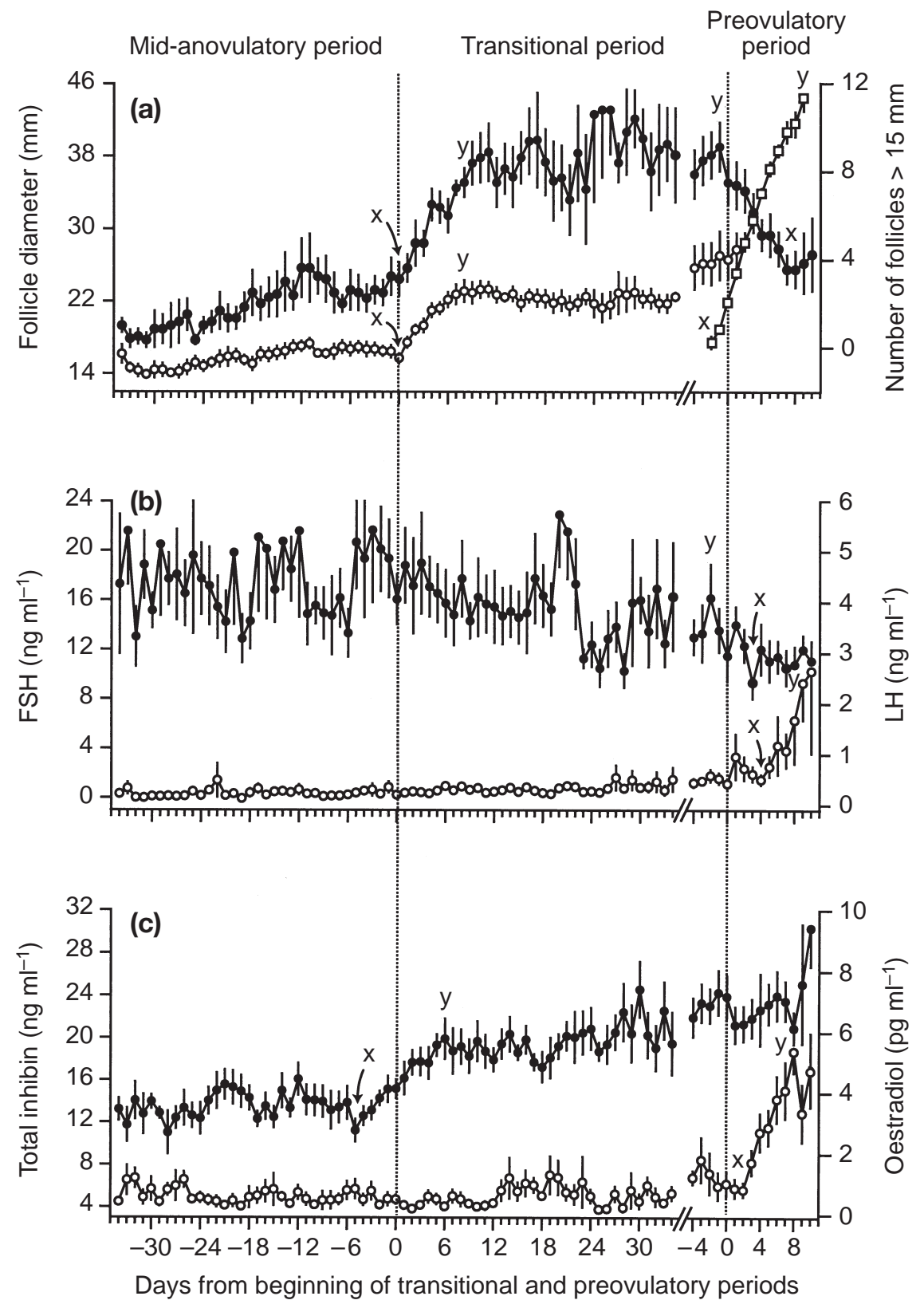

Fig. 2. Mean \pm SEM daily values for (a) number of follicles $\geqslant 15.0 \mathrm{~mm}(-\mathbf{-}-)$, diameter of the largest follicle (—O—) and diameter of the ovulatory follicle (- - ); (b) circulating concentrations of FSH (- - ) and $\mathrm{LH}(-\bigcirc-)$; and (c) circulating concentrations of total inhibin (_- ) and oestradiol (_- - ) during the second-half of the anovulatory season ( $n=8$ mares). Vertical dotted lines indicate the beginning of the transitional period and the beginning of the preovulatory period. There was a significant day effect for the number of follicles $\geqslant 15.0 \mathrm{~mm}$ in diameter $(P<0.0001)$, diameter of the largest follicle $(P<0.0001), \mathrm{LH}(P<0.001)$ and total inhibin $(P<0.0001)$ relative to the beginning of the transitional period. Ovulation occurred, on average, 10 days after the beginning of the preovulatory period. There was a significant day effect for the number of follicles $\geqslant 15.0 \mathrm{~mm}$ in diameter $(P=0.0003)$, diameter of the ovulatory follicle $(P<0.0001), \mathrm{FSH}(P=0.02), \mathrm{LH}(P=0.0003)$ and oestradiol $(P=0.0002)$ relative to the beginning of the preovulatory period. Within endpoints, day means with different letters $(x, y)$ are significantly different $(P<0.05)$.

mares during the preovulatory period (one surge). Of all identified FSH surges, $69 \%$ were not associated with statistically identified waves, as indicated by an interval between the FSH peak and the emergence of a wave of
$>4$ days. An effect of day $(P<0.001)$ for circulating $\mathrm{LH}$ concentrations resulted from a slight progressive increase in mean concentrations during the mid-anovulatory and transitional periods (Fig. 2); LH concentrations remained 

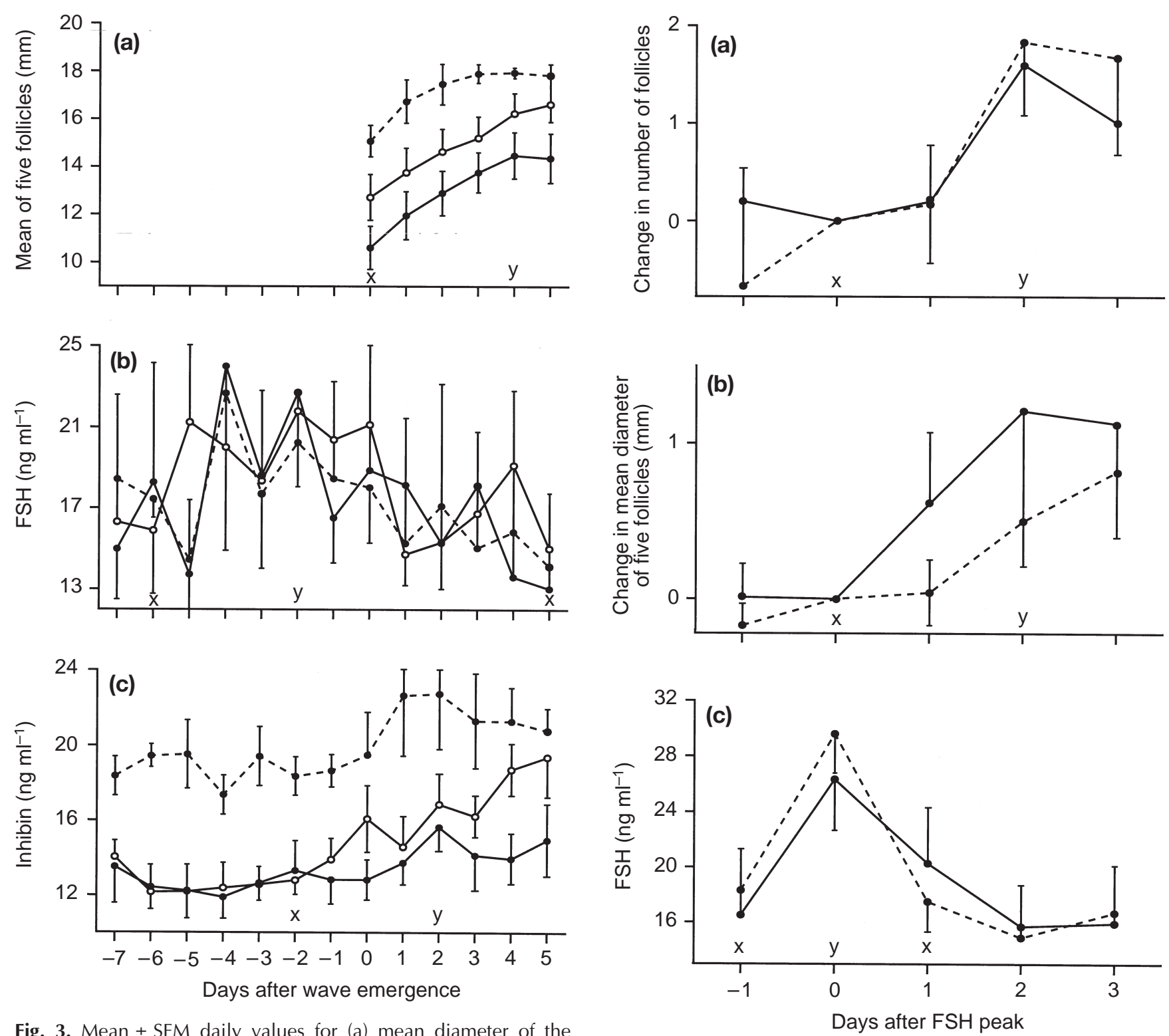

Fig. 3. Mean \pm SEM daily values for (a) mean diameter of the second to sixth largest follicles, (b) circulating FSH concentrations and (c) circulating total inhibin concentrations before and after emergence of waves during the mid-anovulatory period (- - ), beginning of the transitional period ( $-\bigcirc-)$, and middle of the transitional period (------) in mares $(n=8)$. There were effects of day $(P<0.0001)$ and period $(P=0.03)$ for mean diameter of the second to sixth largest follicles, an effect of day $(P=0.01)$ for $\mathrm{FSH}$, and an effect of day $(P=0.0002)$ and period $(P=0.003)$ for total inhibin. Within endpoints, day means with different letters $(x, y)$ averaged over the three periods are significantly different $(P<0.05)$.

below $2 \mathrm{ng} \mathrm{LH} \mathrm{ml}-1$ during the two periods in each mare. $\mathrm{LH}$ increased $(P<0.05)$ during $4-10$ days after the beginning of the preovulatory period.

There was an increase $(P<0.0001)$ in circulating total inhibin concentrations from 5 days before to 6 days after the beginning of the transitional period (Fig. 2). An overall day

Fig. 4. Mean \pm SEM daily values for (a) changes in number of follicles $\geqslant 15.0 \mathrm{~mm}$ in diameter, (b) changes in mean diameter of the second to sixth largest follicles and (c) circulating FSH concentrations relative to an identified peak in FSH during the midanovulatory period (- - ) and transitional period (------) in mares $(n=8)$. There was an effect of day for changes in the number of follicles $\geqslant 15.0 \mathrm{~mm}$ in diameter $(P=0.0002)$, changes in mean diameter of the second to sixth largest follicles $(P=0.02)$, and concentration of FSH $(P<0.0001)$. Within endpoints, day means with different letters $(x, y)$ averaged over the two periods are significantly different $(P<0.05)$.

effect for circulating oestradiol concentrations was not found during the mid-anovulatory and transitional periods. However, sporadic small fluctuations in circulating oestradiol (Table 1) were identified statistically in all mares during the two periods. Mean oestradiol concentrations increased $(P<0.05)$ during $2-8$ days after the beginning of 
Table 1. Follicle and circulating hormone endpoints for the mid-anovulatory, transitional and preovulatory periods in mares

\begin{tabular}{|c|c|c|c|}
\hline Endpoint & Mid-anovulatory period & Transitional period & Preovulatory period \\
\hline Length (days) & $37.5 \pm 7.8^{\mathrm{a}}$ & $41.1 \pm 6.9^{a}$ & $10.1 \pm 0.8^{b}$ \\
\hline Largest follicle $(\mathrm{mm})^{*}$ & $16.0 \pm 0.5^{\mathrm{a}}$ & $22.4 \pm 0.5^{b}$ & $34.8 \pm 1.3^{c}$ \\
\hline \multicolumn{4}{|l|}{ Number of follicles* } \\
\hline $10.0-14.9 \mathrm{~mm}$ & $10.3 \pm 1.5^{\mathrm{a}}$ & $12.0 \pm 1.4^{\mathrm{ab}}$ & $13.5 \pm 1.9^{b}$ \\
\hline$\geqslant 15.0 \mathrm{~mm}$ & $1.7 \pm 0.4^{\mathrm{a}}$ & $7.4 \pm 0.8^{b}$ & $5.7 \pm 0.8^{c}$ \\
\hline $\mathrm{FSH}\left(\mathrm{ng} \mathrm{ml}^{-1}\right)^{*}$ & $17.5 \pm 2.0^{\mathrm{a}}$ & $15.7 \pm 1.9^{a}$ & $11.2 \pm 1.2^{b}$ \\
\hline \multicolumn{4}{|l|}{ Fluctuations } \\
\hline Number per 10 days & $0.8 \pm 0.1$ & $0.6 \pm 0.2$ & $0.3 \pm 0.2$ \\
\hline Amplitude (ng ml-1) & $17.1 \pm 2.7$ & $16.6 \pm 1.4$ & $11.5 \pm 3.1^{\dagger}$ \\
\hline Peak (ng ml-1) & $30.2 \pm 3.7$ & $28.2 \pm 2.8$ & $19.5 \pm 0.3^{+}$ \\
\hline Total inhibin $\left(\mathrm{ng} \mathrm{ml}^{-1}\right)^{*}$ & $13.2 \pm 0.7^{a}$ & $19.8 \pm 1.0^{b}$ & $22.7 \pm 1.4^{c}$ \\
\hline Oestradiol $\left(p g \mathrm{ml}^{-1}\right)^{*}$ & $0.5 \pm 0.1^{\mathrm{a}}$ & $0.7 \pm 0.2^{\mathrm{a}}$ & $2.9 \pm 0.3^{b}$ \\
\hline \multicolumn{4}{|l|}{ Fluctuations } \\
\hline Number per 10 days & $1.5 \pm 0.1$ & $1.2 \pm 0.2$ & $1.0 \pm 0.1$ \\
\hline Amplitude (ng ml-1) & $1.2 \pm 0.3^{\mathrm{a}}$ & $1.7 \pm 0.4^{\mathrm{a}}$ & $5.8 \pm 0.7^{b}$ \\
\hline Peak $\left(\mathrm{ng} \mathrm{ml}^{-1}\right)$ & $1.3 \pm 0.3^{\mathrm{a}}$ & $2.0 \pm 0.5^{a}$ & $6.3 \pm 0.7^{b}$ \\
\hline $\mathrm{LH}\left(\mathrm{ng} \mathrm{ml} \mathrm{l}^{-1}\right)^{*}$ & $0.2 \pm 0.0^{\mathrm{a}}$ & $0.3 \pm 0.0^{\mathrm{a}}$ & $1.0 \pm 0.2^{b}$ \\
\hline
\end{tabular}

Values are mean $\pm \operatorname{SEM}(n=8$ mares $)$.

* Derived from the mean of each mare for each period.

${ }^{+}$Mean \pm SEM of two mares.

a,b,c Means within an endpoint with different superscripts are significantly different $(P<0.05)$.

Table 2. Endpoints for statistically identified follicular waves during mid-anovulatory and transitional periods in mares

\begin{tabular}{|c|c|c|c|}
\hline \multirow[b]{2}{*}{ Endpoint } & \multicolumn{3}{|c|}{ Location of wave } \\
\hline & $\begin{array}{l}\text { Mid-anovulatory period } \\
\quad(n=8 \text { waves })\end{array}$ & $\begin{array}{l}\text { Beginning of transitional period } \\
\qquad(n=8 \text { waves })\end{array}$ & $\begin{array}{l}\text { Middle of transitional period } \\
\qquad(n=5 \text { waves })\end{array}$ \\
\hline \multicolumn{4}{|l|}{ Emergence relative to beginning } \\
\hline Emergence relative to ovulation (days) & $-69.0 \pm 3.6$ & $-54.0 \pm 7.5$ & $-26.0 \pm 4.1$ \\
\hline \multicolumn{4}{|l|}{$\begin{array}{l}\text { Mean diameter of } 2 \text { nd to } 6 \text { th largest } \\
\text { follicles }\end{array}$} \\
\hline At emergence $(\mathrm{mm})$ & $10.6 \pm 0.9^{a}$ & $12.6 \pm 0.9^{a}$ & $15.7 \pm 1.1^{b}$ \\
\hline At maximum $(\mathrm{mm})$ & $15.0 \pm 0.9^{a}$ & $19.4 \pm 0.6^{b}$ & $19.9 \pm 0.8^{b}$ \\
\hline Largest follicle of the wave (mm) & $18.9 \pm 0.6^{\mathrm{a}}$ & $24.9 \pm 0.9^{b}$ & $28.0 \pm 3.4^{b}$ \\
\hline
\end{tabular}

Values are means \pm SEM

a,b Means within an endpoint with different superscripts are significantly different $(P<0.05)$.

the preovulatory period. Single-point follicle and hormone means and the results of statistical analyses for the midanovulatory, transitional and preovulatory periods are shown (Table 1).

\section{Follicular waves}

Two to five follicular waves, as indicated by a significant increase in the mean diameter of the second to sixth largest follicles (Fig. 1), were detected in each mare during the study. During the mid-anovulatory period, two mares had two and three identified waves, five mares had one identified wave, and one mare had no identified wave. An identified wave at the beginning of the transitional period occurred in all mares, in temporal association with the increase in mean diameter of the largest follicle and the number of follicles $\geqslant 15 \mathrm{~mm}$ in diameter (Fig. 2). During the remaining transitional period, one wave was detected in each of four mares and two waves were detected in one mare. A wave was statistically identified at the end of the transitional period in temporal association with a growing ovulatory follicle in only one of eight mares.

Results of comparing follicular waves occurring during the mid-anovulatory period and at the beginning and middle of the transitional period are shown (Table 2; Fig. 3). Mean diameter of the second to sixth largest follicles was larger $(P<0.05)$ for waves during the middle of the transitional period than for waves during the mid- 
anovulatory period on each day during days $0-5$ after wave emergence (Fig. 3). Averaged over all periods, FSH concentrations increased $(P<0.05)$ and then decreased $(P<0.05)$ during 6 days before to 5 days after wave emergence. However, there was no effect of period or a period by day interaction for $\mathrm{FSH}$ concentrations associated with waves. An increase $(P<0.05)$ in total inhibin concentrations occurred from 2 days before to 2 days after emergence of waves for the three periods combined. Total inhibin concentrations were higher $(P<0.05)$ for waves during the middle of the transitional period than for waves during the mid-anovulatory period and beginning of the transitional period at each day from 7 days before to 1 day after wave emergence, except on the day of wave emergence. Concentrations were higher $(P<0.05)$ at day 4 after wave emergence for waves during the middle of the transitional period than for waves during the midanovulatory period. No significant effect was found for concentrations of oestradiol or $\mathrm{LH}$ relative to wave emergence.

Averaged over the mid-anovulatory and transitional periods, there were increases in the number of follicles $\geqslant 15.0 \mathrm{~mm}$ in diameter $(P<0.05)$ and diameter of the second to sixth largest follicles $(P<0.05)$ after an identified FSH peak (Fig. 4). Circulating FSH concentrations from 1 day before to 3 days after the peak of an FSH surge were not significantly different between the two periods.

\section{Discussion}

The presence of a mid-anovulatory period (largest follicle $<21 \mathrm{~mm}$ in diameter) in each mare from the beginning of the study (29 January) to an average of 8 March or 52 days before the first ovulation of the year is consistent with the report (Turner et al., 1979) that follicles $>20 \mathrm{~mm}$ in diameter were not detected in ponies until an average of mid-March or about 60 days before the onset of the ovulatory season. An increase in the diameter of the largest follicle and numbers of follicles $\geqslant 15 \mathrm{~mm}$ in diameter occurred during the first 8 days of the transitional period and represented an identified follicular wave in all mares. This distinct increase and subsequent maintenance of enhanced follicular activity allowed normalization of the data using the increase as a reference point. This characteristic of the anovulatory season has not been reported previously, and the 8 days increase contrasts with the reported progressive increases in mean follicle diameters and numbers during the 60-75 days before the first ovulation of the year in ponies (Freedman et al., 1979; Turner et al., 1979) and horses (Carnevale et al., 1997). As the short-term increases in follicle diameter and numbers at the beginning of the transitional period occurred at a variable time before the first ovulation in individual mares, the increases probably would have been masked in the previous studies by the normalization of data to the first ovulation of the year. In the present study, three of the eight mares developed a large $(\geqslant 30 \mathrm{~mm})$ anovulatory follicle before developing an ovulatory follicle. In previous studies, seven of 15 (Ginther, 1990) and nine of ten (Watson et al., 2002) mares developed one to three large anovulatory follicles during the transition into the ovulatory season. The reason for the apparent lower frequency of such mares in the present study than in the study by Watson et al. (2002) is not known.

The results of the present study support the hypothesis that follicular waves develop throughout the later half of the anovulatory season in mares. This hypothesis has not been tested previously in mares, but waves have been reported during the anovulatory season in ewes (Bartlewski et al., 1999; Evans et al., 2001). Minor waves developed in all mares during the mid-anovulatory period and the transitional period, except for mare $\mathrm{C}$ which had a short midanovulatory period. A major wave (largest follicle $\geqslant 30 \mathrm{~mm}$ ) developed in three mares during the transitional period. A background of larger follicles during the transitional period than during the mid-anovulatory period resulted in the detection of wave emergence at a larger mean diameter during the middle of the transitional period than during the mid-anovulatory period. There was agreement between statistically identified waves and an apparent synchronous growth of several individual follicles during all periods of the current study. However, inspection of data for individual follicles also indicated that some waves were not detected by significant increases in the mean diameter of the second to sixth largest follicles. A statistical wave seemed associated with emergence of the ovulatory follicle in only one of eight mares. In three of the remaining mares, an apparent wave was detected by inspection of the profiles of the six largest follicles. In the other mares, the presence of a wave in association with the emergence of the ovulatory follicle was not apparent by visual inspection. The obscurement of waves seemed attributable primarily to the masking effect of regressing follicles from a previous minor or major wave. Failure to identify waves does not diminish the objectivity of the study because only the statistically identified waves were used to study hormonal changes associated with waves. Although follicles developed in clusters or waves during the three periods, the development of other follicles in isolation has not been eliminated by this study.

The hypothesis of a temporal association between FSH increases and follicular waves during the anovulatory season was supported and was demonstrated both by normalizing $\mathrm{FSH}$ data to wave emergence and by normalizing follicle data to $\mathrm{FSH}$ peaks. A temporal relationship between $\mathrm{FSH}$ surges and the emergence of a cohort of follicles (wave) during the anovulatory season has not been reported previously; however, FSH surges have been reported, anecdotally, in temporal association with the emergence of large anovulatory follicles near the end of transition (Ginther, 1992; Watson et al., 2002). A similar relationship between increases in $\mathrm{FSH}$ concentrations and the emergence of follicular waves occurs during the 
ovulatory season (Ginther and Bergfelt, 1993) and pregnancy (Ginther and Bergfelt, 1992b) in mares, and during the anovulatory season in ewes (Evans et al., 2001). However, FSH surges were also identified in the present study that were not associated with waves, in agreement with recent reports in mares (Watson et al., 2002) and ewes (Evans et al., 2001). In the present study, the changes in FSH concentrations associated with follicular waves were not different among the mid-anovulatory period, beginning of the transitional period, and middle of the transitional period. The increase in follicle diameters that distinctly separated the mid-anovulatory and transitional periods, therefore, is not attributable to differences in the FSH surges. Changes in follicular responsiveness to the wavestimulating $\mathrm{FSH}$ may have been involved. In this regard, changes in concentrations of follicular-fluid factors may modulate the sensitivity of follicles to FSH during the ovulatory season (Donadeu and Ginther, 2002). An increase in $\mathrm{FSH}$ receptor expression in temporal association with gonadal recrudescence at the end of the non-breeding season (Sanford et al., 2002) and an increase in the half-life of pituitary $\mathrm{FSH}$ isoforms from the anovulatory to the ovulatory season (Moore et al., 2000) have been described in sheep, and alternatively may be involved in an increase in the follicle response to gonadotrophins at the beginning of the transitional period in mares.

The temporal relationships between follicular waves and changing inhibin concentrations have apparently not been reported previously for anovulatory mares. In the present study, an increase in circulating concentrations of total inhibin encompassed the development of follicular waves during the mid-anovulatory and transitional periods. In addition, total inhibin concentrations increased with the increase in follicle diameters and numbers at the beginning of the transitional period and concentrations were highest during the preovulatory period. Consistent with the present results, mean plasma concentrations of inhibin $\mathrm{A}$ and proand $-\alpha C$ inhibins were lowest during the middle of the anovulatory season, higher during the stage of large anovulatory follicles $(25-40 \mathrm{~mm})$ and highest when an ovulatory follicle was present (Watson et al., 2002). Thus, the conclusions were similar when based on assay of total inhibin (the present study) as when based on assay of individual inhibin isoforms (Watson et al., 2002). A positive relationship between follicle diameters and numbers and circulating total inhibin concentrations has also been reported during the ovulatory season (Donadeu and Ginther, 2001). A role for inhibin in the suppression of circulating $\mathrm{FSH}$ in seasonally anovulatory mares was suggested by the temporal relationships between an increase in circulating total inhibin and a decrease in FSH concentrations during wave development and is similar to results for the ovulatory season (Bergfelt et al., 2001; Donadeu and Ginther, 2001). A role for a follicular factor, presumably inhibin, in the suppression of $\mathrm{FSH}$ has been suggested, based on progressive decreases in FSH pulse amplitude and mean daily circulating FSH concentrations
(Hines et al., 1991) and on GnRH-induced pituitary FSH secretion (Silvia et al., 1987) during the transition into the ovulatory season. In the present study, a decrease (not significant) in mean daily circulating FSH occurred throughout the transitional period in temporal association with the high circulating concentrations of inhibin. Maximal FSH suppression during the preovulatory period presumably was accounted for by the high circulating inhibin, as well as oestradiol (Gastal et al., 1999).

Circulating oestradiol concentrations were low during the mid-anovulatory and transitional periods compared with the first preovulatory period, in agreement with previous reports (Oxender et al., 1977; Seamans et al., 1982), and did not increase with follicular wave emergence during the mid-anovulatory and transitional periods. Watson et al. (2002), however, reported a small increase in circulating oestradiol during the growth of large follicles $(25-40 \mathrm{~mm})$ in late transitional mares. Large $(>30 \mathrm{~mm})$ anovulatory follicles produce limited oestradiol and this production increases at the end of the transition into the ovulatory season (Davis and Sharp, 1991). Watson and Alzi'abi (2002) concluded that the low steroidogenic capacity of anovulatory follicles is probably due to poor vascularity and development of the theca layer. In the present study, subtle statistical fluctuations in circulating concentrations of oestradiol were detected sporadically during the midanovulatory and transitional periods, and the fluctuations often did not appear to be associated with growth of follicles. Oestradiol concentrations associated with these fluctuations may be related to the reported occurrence of unseasonal oestrus during the anovulatory season in intact mares (Ginther, 1974; Asa et al., 1980a; Ginther, 1990) and ovariectomized mares (Asa et al., 1980a). A role for adrenal steroids in causing unseasonal oestrous behaviour in mares has been suggested (Asa et al, 1980b; Pope et al., 1995). On the basis of these results, the sporadic and slight fluctuations in oestradiol may not have been of ovarian origin.

A slight increase in mean circulating LH concentrations over the mid-anovulatory and transitional periods may reflect a progressive increase in LH pulse frequency during the last 2 months of the anovulatory season in mares (Fitzgerald et al., 1987). Pituitary LH concentrations gradually increase during the transition into the ovulatory season (Silvia et al., 1986) and circulating LH concentrations apparently reflect pituitary content in transitional mares (Silvia et al., 1987). Despite the reports of a gradual increase, circulating LH concentrations associated with follicular wave emergence were not different between the mid-anovulatory and transitional periods in the present study. Further study is needed to determine whether an increase in $\mathrm{LH}$ accounts for the increase in follicle growth associated with a follicular wave at the beginning of the transitional period. It was suggested by Sharp et al. $(1991,2001)$ that increasing circulating oestradiol concentrations at the end of the anovulatory season act to stimulate pituitary LH synthesis and secretion resulting in an ovulatory $\mathrm{LH}$ surge in mares. This suggestion 
is consistent with the present results of a preovulatory increase in circulating $\mathrm{LH}$ concentrations following an increase in circulating oestradiol.

In summary, the results of the present study indicate that follicular waves occur even during the limited follicular activity of the mid-anovulatory period (largest follicle $<21 \mathrm{~mm}$ ). Temporal relationships indicate that follicular waves were stimulated by increases in circulating $\mathrm{FSH}$ concentrations during the mid-anovulatory and transitional periods. In addition, the growing follicles produced inhibin, which would account, at least partly, for the subsequent suppression of $\mathrm{FSH}$ secretion. A distinct increase in follicle diameter associated with a follicular wave occurred at the beginning of the transitional period. However, the $\mathrm{FSH}$ surges associated with waves were similar during the midanovulatory and transitional periods, indicating that factors other than the nature of $\mathrm{FSH}$ surges account for the increased follicle responsiveness at the beginning of the transitional period.

The authors thank J. A. O'Sullivan for technical assistance, A. F. Parlow from the National Hormone and Pituitary Program for gonadotrophin radioimmunoassay reagents, and D. R. Bergfelt for manuscript review.

\section{References}

Alexander SL and Irvine CHG (1991) Control of onset of the breeding season in the mare and its artificial regulation by progesterone treatment Journal of Reproduction and Fertility Supplement 44 307-318

Asa CS, Goldfoot DA, Garcia MC and Ginther OJ (1980a) Sexual behavior in ovariectomized and seasonally anovulatory pony mares (Equus caballus) Hormones and Behavior 14 46-54

Asa CS, Goldfoot DA, Garcia MC and Ginther OJ (1980b) Dexamethasone suppression of sexual behavior in the ovariectomized mare Hormones and Behavior 14 55-64

Bartelwski PM, Beard AP and Rawlings NC (1999) Ovarian function in ewes during the transition from breeding season to anoestrus Animal Reproduction Science 57 51-66

Bergfelt DR, Gastal EL and Ginther OJ (2001) Response of estradiol and inhibin to experimentally reduced luteinizing hormone during follicle deviation in mares Biology of Reproduction 65 426-432

Bogh IB, Hoier R, Synnestvedt B and Greeve T (2000) Steroid concentrations in follicular fluid aspirated repeatedly from transitional and cyclic mares Theriogenology 54 877-888

Carnevale EM, Hermenet MJ and Ginther OJ (1997) Age and pasture effects on vernal transition in mares Theriogenology 47 1009-1018

Davis SD and Sharp DC (1991) Intra-follicular and peripheral steroid characteristics during vernal transition in the pony mare Journal of Reproduction and Fertility Supplement 44 333-340

Donadeu FX and Ginther OJ (2001) Effect of number and diameter of follicles on plasma concentrations of inhibin and $\mathrm{FSH}$ in mares Reproduction 121 897-903

Donadeu FX and Ginther OJ (2002) Changes in concentrations of follicular fluid factors during follicle selection in mares Biology of Reproduction 66 1111-1118

Eagle RC and Tortonese DJ (2000) Characterization and distribution of gonadotrophs in the pars distalis and pars tuberalis of the equine pituitary gland during the estrous cycle and seasonal anestrus Biology of Reproduction 63 826-832

Evans ACO, Duffy P, Quinn KM, Knight PG and Boland MP (2001) Follicular waves are associated with transient fluctuations in FSH but not oestradiol or inhibin-A concentrations in anoestrous ewes Animal Science 72 547-554
Fitzgerald BP, I'Anson H, Legan SJ and Loy RG (1985) Changes in patterns of luteinizing hormone secretion before and after the first ovulation in the postpartum mare Biology of Reproduction 33 316-323

Fitzgerald BP, Affleck KJ, Barrows SP, Murdoch WL, Barker KB and Loy RG (1987) Changes in LH pulse frequency and amplitude in intact mares during the transition into the breeding season Journal of Reproduction and Fertility $\mathbf{7 9}$ 485-493

Freedman LJ, Garcia MC and Ginther OJ (1979) Influence of photoperiod and ovaries on seasonal reproductive activity in mares Biology of Reproduction 20 567-574

Gastal EL, Gastal MO and Ginther OJ (1999) Experimental assumption of dominance by a smaller follicle and associated hormonal changes in mares Biology of Reproduction 61 724-730

Ginther OJ (1974) Occurrence of anestrus, estrus, diestrus, and ovulation over a 12-month period in mares American Journal of Veterinary Research 35 1173-1179

Ginther OJ (1990) Folliculogenesis during the transitional period and early ovulatory season in mares Journal of Reproduction and Fertility $\mathbf{9 0}$ $311-320$

Ginther OJ (1992) Reproductive Biology of the Mare: Basic and Applied Aspects pp 141-144, 151. Equiservices Publishing, Cross Plains, WI

Ginther OJ (1995) Ultrasonic Imaging and Animal Reproduction: Book 1, Fundamentals pp 94-95. Equiservices Publishing, Cross Plains, WI

Ginther OJ and Bergfelt DR (1992a) Ultrasonic characterization of follicular waves in mares without maintaining identity of individual follicles Journal of Equine Veterinary Science 12 349-354

Ginther OJ and Bergfelt DR (1992b) Associations between FSH concentrations and major and minor follicular waves in pregnant mares Theriogenology 38 807-821

Ginther OJ and Bergfelt DR (1993) Growth of small follicles and concentrations of FSH during the equine oestrous cycle Journal of Reproduction and Fertility 99 105-111

Hines KK, Affleck KJ, Barrows SP, Murdoch WL, Fitzgerald BP and Loy RG (1991) Follicle-stimulating hormone pulse amplitude decreases with the onset of the breeding season in the mare Biology of Reproduction $\mathbf{4 4}$ 516-521

Moore LG, Ng Chie W, Hudson NL and McNatty KP (2000) Isoforms and half-life of FSH from sheep with different reproductive states Journal of Endocrinology 165 185-192

Nagata S-I, Tsunoda N, Nagamine N, Tanaka Y, Taniyama H, Nambo Y, Watanabe G and Taya K (1998) Testicular inhibin in the stallion: cellular source and seasonal changes in its secretion Biology of Reproduction $\mathbf{5 9}$ $62-68$

Oxender WD, Noden PA and Hafs HD (1977) Estrus, ovulation, and serum progesterone, estradiol, and LH concentrations in mares after an increased photoperiod during winter American Journal of Veterinary Research 38 203-207

Pope NS, Sargent G and Kesler DJ (1995) The dexamethasone induced suppression of androgen secretions suppressed estrous behavior in pony mares during winter Journal of Equine Veterinary Science 15 119-123

Roser JF, McCue PM and Hoye E (1994) Inhibin activity in the mare and stallion Domestic Animal Endocrinology 11 87-100

Sanford LM, Price CA, Leggee DG, Baker SJ and Yarney TA (2002) Role of $\mathrm{FSH}$, number of $\mathrm{FSH}$ receptors and testosterone in the regulation of Inhibin secretion during the seasonal testicular cycle of adult rams Reproduction 123 269-280

SAS Institute, Inc (1989) SAS/STAT TM User's Guide, Version 6, Edn. 4. SAS Institute, Inc., Cary, NC

SAS Institute, Inc (1995) Introduction to the MIXED Procedure SAS Institute, Inc., Cary, NC

Seamans KW and Sharp DC (1982) Changes in equine follicular aromatase activity during transition from winter anoestrus Journal of Reproduction and Fertility Supplement 32 225-233

Sharp DC, Grubaugh WR, Weithenauer J, Davis SD and Wilcox CJ (1991) Effects of steroid administration on pituitary luteinizing hormone and follicle-stimulating hormone in ovariectomized pony mares in the early spring; pituitary responsiveness to gonadotropin-releasing hormone and pituitary gonadotropin content Biology of Reproduction 44 982-990 
Sharp DC, Wolfe MW, Cleaver BD and Nilson J (2001) Effects of estradiol$17 \beta$ administration on steady-state messenger ribonucleic acid (mRNA) encoding equine $\alpha$ and $\mathrm{LH} / \mathrm{CG} \beta$ subunits in pituitaries of ovariectomized pony mares Theriogenology 55 1083-1093

Silvia PJ, Squires EL and Nett TM (1986) Changes in the hypothalamic-hypophyseal axis of mares associated with seasonal reproductive recrudescence Biology of Reproduction 35 897-905

Silvia PJ, Squires EL and Nett TM (1987) Pituitary responsiveness of mares challenged with $\mathrm{GnRH}$ at various stages of the transition into the breeding season Journal of Animal Science 64 790-796

Turner DD, Garcia MC and Ginther OJ (1979) Follicular and gonadotropic changes throughout the year in pony mares American Journal of Veterinary Research 40 1694-1700
Watson ED and Al-zi'abi MO (2002) Characterization of morphology and angiogenesis in follicles of mares during spring transition and the breeding season Reproduction 124 227-234

Watson ED, Heald M, Tsigos A, Leask R, Steele M, Groome NP and Riley SC (2002) Plasma FSH, inhibin A and inhibin isoforms containing proand $-\alpha \mathrm{C}$ during winter anoestrus, spring transition and the breeding season in mares Reproduction 123 535-542

Received 18 April 2002.

First decision 16 July 2002.

Revised manuscript received 6 August 2002.

Accepted 6 September 2002. 